ISSN 0258-7122

Bangladesh J. Agril. Res. 34(3) : 373-384, September 2009

\title{
STUDY ON PHENOLOGY AND YIELDING ABILITY OF BASMATI FINE RICE GENOTYPES AS INFLUENCED BY PLANTING DATE IN AMAN SEASON
}

\author{
M.A. MANNAN ${ }^{1}$, M.S.U. BHUIYA ${ }^{2}$ \\ S.M.A. HOSSAIN ${ }^{2}$ AND M.I.M. AKHAND ${ }^{3}$
}

\begin{abstract}
The experiment was conducted at the Bangladesh Rice Research Institute Farm, Gazipur in Aman season to determine the optimum time of planting and to find out the genotypes having high yield potential. Fine rice genotypes Basmati PNR, Basmati 370, Basmati 375, and Basmati-D were transplanted from 22 July and continued upto 7 October at an interval of 15 days both in 1999 and 2000. Thirty-day old seedlings were transplanted at a spacing of $20 \mathrm{~cm} \mathbf{x} 15 \mathrm{~cm}$. The tallest plant was found in the early-planted crop at maturity. Crop planted from 7 August to 7 September gave more number of tillers per $\mathrm{m}^{2}$, panicles per $\mathrm{m}^{2}$ and grains per panicle which resulted in higher grain yield. Compared to the 22 August planting, grain yield decreased by 11, 10, 10, 26, and 61 percent, respectively, when the crop was planted on 22 July, 7 August, 7 September, 22 September, and 7 October. The growth duration of the genotypes decreased with the advancement of planting date. Among the genotypes, Basmati PNR gave maximum grain yield followed by Basmati-D due to more number of panicles and lower percentage of spikelet sterility. The lower grain yield was found in Basmati 370 irrespective of planting date due to lower number of panicles and high percentage of spikelet sterility. The Basmati PNR matured 5-12 days earlier than the rest of the test genotypes. Thus, fine rice Basmati PNR and Basmati-D were most suitable to obtain higher grain yield when planted within 17-21 August.
\end{abstract}

Key Words: Basmati rice, time of planting, Aman season.

\section{Introduction}

Farmers cultivate coarse and fine rice genotypes to meet their food demand as rice provides vitamin and other nutrients of common people. The fine rice, especially the Basmati rice (aromatic) is grown in pocket area for their family consumption. Basmati grains are long (length $>6.0 \mathrm{~mm}$ ), slender and have wider acceptance to the consumers and are commonly used in special occasion or in festivals owning to its fineness as well as quality (Yoshihashi, 2005). The demand of Basmati rice has been increasing as the country is being more prosperous and approaching self-sufficiency in rice production (BRRI, 2004). Grain yield of Basmati rice is comparatively low than the coarse rice. But the

\footnotetext{
${ }^{1}$ Agronomy Division, BRRI, Gazipur, ${ }^{2}$ Department of Agronomy, BAU, Mymensingh, ${ }^{4}$ Research Fellow, Bangabandhu Sheikh Mujibur Rahman Agricultural University, Gazipur, Bangladesh.
} 
price of Basmati rice, especially the aromatic one is 2-3 times higher than the coarse rice ((Biswas et al., 1992).

The climatic condition of Bangladesh is most suitable to produce quality Basmati rice in Aman season (BRRI, 1997). The production of Basmati rice can be increased with the manipulation of transplanting time and selection of genotypes having high yield potential (Singh and Singh, 2000).

The time of transplanting has a great influence on the growth, yield and yield contributing characters of rice (Islam et al., 1999). Sometimes transplanting in optimum time is not possible due to untimely rainfall or delay recession of floodwater. Moreover, due to genetic variability, the potentiality of the genotypes expressed differently due to planting in different dates. The early planted photoperiod sensitive rice varieties passed lag vegetative phase which increased tallness as well as biomass that prone to lodge during grain filling stage. On the contrary, the late planted crop suffers due to low temperature during reproductive stage and sometimes panicle can not emerge properly and some portions remain within the leaf sheath and consequently increases spikelet sterility and gives low grain yield (Canet, 1986). Thus, by adjustment of transplanting time, the plant can take advantage of natural conditions favourable for its growth (BRRI, 2004). The potential genotypes can give satisfactory yield when planted in appropriate time. The information for planting Basmati rice in optimum time and potential genotypes for growing in Aman season is still lacking.

Based on the above propositions, the present study was undertaken to find out the optimum planting time and to select the Basmati genotypes having high yield potential to increase production in Aman season.

\section{Materials and Method}

Basmati rice genotypes Basmati PNR, Basmati 370, Basmati 375, and Basmati-D were transplanted on 22 July (Julian date 203), 7 August (Julian date 218), 22 August (Julian date 233), 7 September (Julian date 248), 22 September (Julian date 263), and 7 October (Julian date 278) in Aman season both in 1999 and 2000. Thirty-day old seedlings using 2-3 seedlings were transplanted spaced at $20 \mathrm{~cm} \times 15 \mathrm{~cm}$. The treatments were distributed in a split-plot design, placing planting time in the main plot and genotypes in the sub plot and replicated thrice. Fertilizers were applied @ 60-40-40-10 kg N, $\mathrm{P}_{2} 0_{5}, \mathrm{~K}_{2} 0$, and S/ha, respectively, through urea, triple super phosphate, muriate of potash, and gypsum during final land preparation except urea. Urea was top-dressed in three equal splits at 15, 30 days after transplanting (DAT) and at 5 days before panicle emergence (BRRI, 2004). The crop field was kept weed free by three hand weedings at different growth stages.

Five destructive sample hills were collected from each individual plot out side of the harvested area to measure plant height, tiller number, and dry matter 
at different growth stages at 15-day intervals started from 30 DAT. After recording height and tiller the same sample was dried in an oven at $70{ }^{\circ} \mathrm{C}$ temperature for 72 hours for drying. For yield components, five hills were selected randomly from each plot before harvest and for grain yield, five square meter areas were harvested from the center of the plot avoiding border rows. The grain yield was adjusted to $14 \%$ moisture content and expressed in ton/ha. The straw was dried in the sun (5 days) until complete drying before weighing.

The degree of photoperiod sensitivity was calculated by using the following formula (Ghosh and Saran, 1982). Degree of photoperiod sensitivity $\frac{X-Y}{X} \times 100$

Where, $\mathrm{X}=$ Flowering duration due to long day effect (Seeding on 22 June)

$Y=$ Flowering duration due to short day effect (Seeding on 7 September).

\section{Regression analysis to determine optimum planting date}

Optimum date of transplanting of the test varieties were determined by regressing the grain yield with the transplanting dates. Functional relationship between planting date and rice yields was described by the following quadratic equation (Eqn.).

$Y=a+b P+c P^{2}$

Where $Y$ is rice yield (kg/ha), $P$ is transplanting date (Julian date), a is intercept (estimated yield) initial planting date, $b$ and $c$ are coefficients, respectively. Differentiating $Y$ with respect to planting date $P$ of the Eqn. (1) gives planting date for maximum yield. The estimated planting time for higher yield would be at the point of

$$
\begin{aligned}
& \frac{d Y}{d P}=0 \\
& \text { or, } b+2 c P=0 \\
& \text { or } \frac{d Y}{d P}=0=b+2 c P \\
& \text { or, } P=-\frac{b}{2 c}
\end{aligned}
$$

\section{Results and Discussion}

\section{Plant height, tiller and dry matter production}

Plant height, tiller number, and dry matter of test varieties varied significantly due to the variation of transplanting dates. The short plants, less tillers, and dry 
matter were observed in early planted (22 July) crop and these characters increased successively with the advancement of planting date until 7-22 September and again declined thereafter irrespective of growth stages upto 60 DAT. Short plant, less tillers, and dry matter of the early planted crop were due to higher cloudy hours, less bright sunshine hour, and excess rain water standing in the field that hampered crop growth and development. As the weather became cloud-free in September, the crop growth became faster had short plants, less tillers and dry matter due to cold spell at night. However, at maturity, taller plant was found in the early-planted crop, and this might be due to the longer vegetative growth phase, which enhanced to increase height. The length of vegetative phase of rice progressively reduced due to delayed planting resulting in short plant height. The results are in conformity with the findings of Salam et al. (2004).

The Basmati 375 gave significantly taller plant followed by Basmati 370 and Basmati-D, while Basmati PNR showed the shortest plant at different growth stages irrespective of planting dates. The significantly highest number of tillers plant and dry matter were found in Basmati-D, while the lowest number of tillers in tall plant Basmati 370 and Basmati 375. The less amount of dry matter was observed in short stature plant of Basmati PNR irrespective of growth stages. The findings of Angrish et al. (1997) had similarity with these results. The variation of dry matter of rice genotypes due to transplanting in different dates was described by regression analysis (Fig. 1).

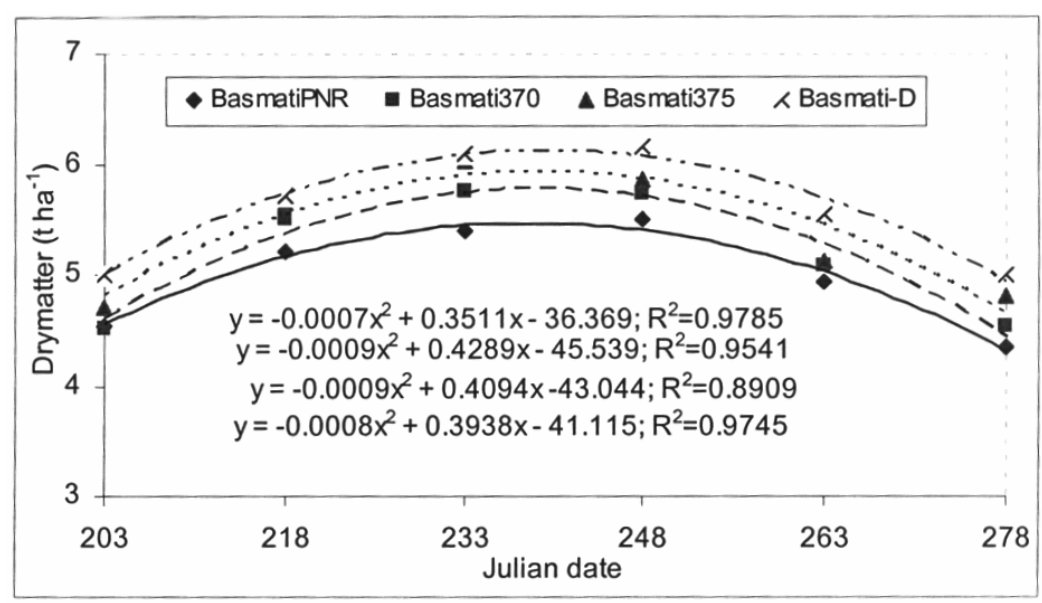

Fig. l. Dry matter of Basmati rice as affected by planting date at 60 DAT (Aman season).

\section{Yield components}

Transplanting of rice on 22 August produced the highest number of panicles per $\mathrm{m}^{2}$ than those planted early or late in both the years. The number of panicles gradually decreased as planting was delayed beyond 22 August. Late planted 
crop of 7 October produced least number of panicles. Similar trend was also observed by Islam et al. (1999). Significantly higher number of panicles per $\mathrm{m}^{2}$ was found in Basmati-D followed by Basmati PNR, while the lowest number of panicles per $\mathrm{m}^{2}$ was observed in Basmati 370 . The variation of panicles among the genotypes might be due to the genetic potentiality.

The longest panicles per $\mathrm{m}^{2}$ was found in the crop planted on 22 July and the length decreased successively in each delayed planting. These findings are in conformity with the results of Chopra et al. (2003). The longest panicle was found in Basmati 375, which was identically followed by Basmati 370. While, the shortest panicle was found in Basmati PNR irrespective of planting dates.

Higher number of grains per panicle was found in August planted crop probably due to the interaction of higher solar radiation associated with optimum temperature. The early-planted crop on 22 July lodged during grain filling stage that caused decreased grains per panicle. On the other hand, grains per panicle was drastically reduced in late-planted (7 October) crop due to cold. Basmati PNR and Basmati-D planted in August produced the maximum number of grains/panicle and it decreased progressively as the planting delayed beyond 7 September. The lowest number of grains/panicle was recorded in Basmati 370.

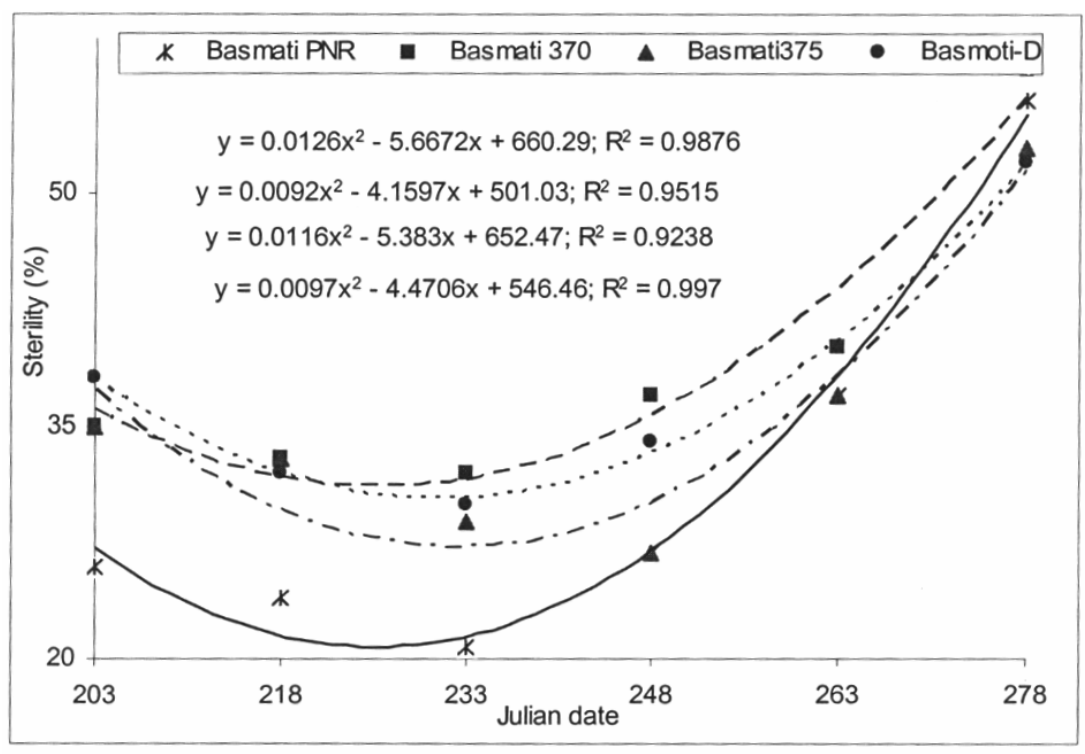

Fig. 2. Sterility (\%) of Basmati rice as affected by planting date (Aman season).

The high spikelet sterility was found in the crop planted on July as well on late September and in October. The lowest percentage of spikelet sterility was observed on 22 August planted crop. The late-planted crop was adversely 
affected by low temperature during panicle emergence to flowering stages. The quadratic relationship was found between planting time and spikelet sterility irrespective of genotypes (Fig. 2). The low percentage of spikelet sterility was found in Basmati PNR upto August and beyond that the sterility (\%) was lower in Basmati 375. Similar findings were reported by BRRI (2003). The percentage of spikelet sterility associated with the tallness of the plant, which was prone to lodge during grain filling stage and increased sterility.

The individual grain weight of rice slightly varied due to planting of rice on different dates. Heavier grain weight was found in early planted crop and grain weight decreased beyond 22 August planting. Probably the grain filling was hampered due to late planting and decreased individual seed weight. Heavier grain was found in Basmati PNR followed by Basmati 375 and Basmati 370, while the lightest grain was found in Basmati-D.

\section{Grain yield}

Early transplanted crop on 22 July showed lower grain yield and the yield progressively increased with the advancement of planting dates upto 22 August and decreased thereafter. Compared to the 22 August planting, grain yield decreased by $11,10,10,26$, and $61 \%$, respectively, when the crop was planted on 22 July, 7 August, 7 September, 22 September, and 7 October. Higher grain yield on 22 August crop might be due to more number of panicles and higher number of grains per panicle. The availability of more sunshine hours in late August was favourable to increase yield components (Singh and Zaman, 1991). The optimum planting time 17-29 August (228-240 Julian date) was estimated through regression analysis (Fig. 3).

These findings are in agreement with the observations made by BRRI (2003) for cultivation of aromatic fine rice in the Aman season. The early-planted photoperiod sensitive crop was in the field for longer period to complete their life cycle which enhanced biomass production and tallness of plant resulting prone to lodge during grain filling period and decreased grain yield (Kropff and Spitters, 1991) Thus, grain yield of early-planted (22 July to 7 August) crop gave lower yield than the 22 August planted crop. Late planted (beyond 22 September) crop showed lower number of panicles per $\mathrm{m}^{2}$, grains per panicle and higher percentage of spikelet sterility that resulted in lower grain yield. Almost similar response was also noticed by Singh et al. (1997). 


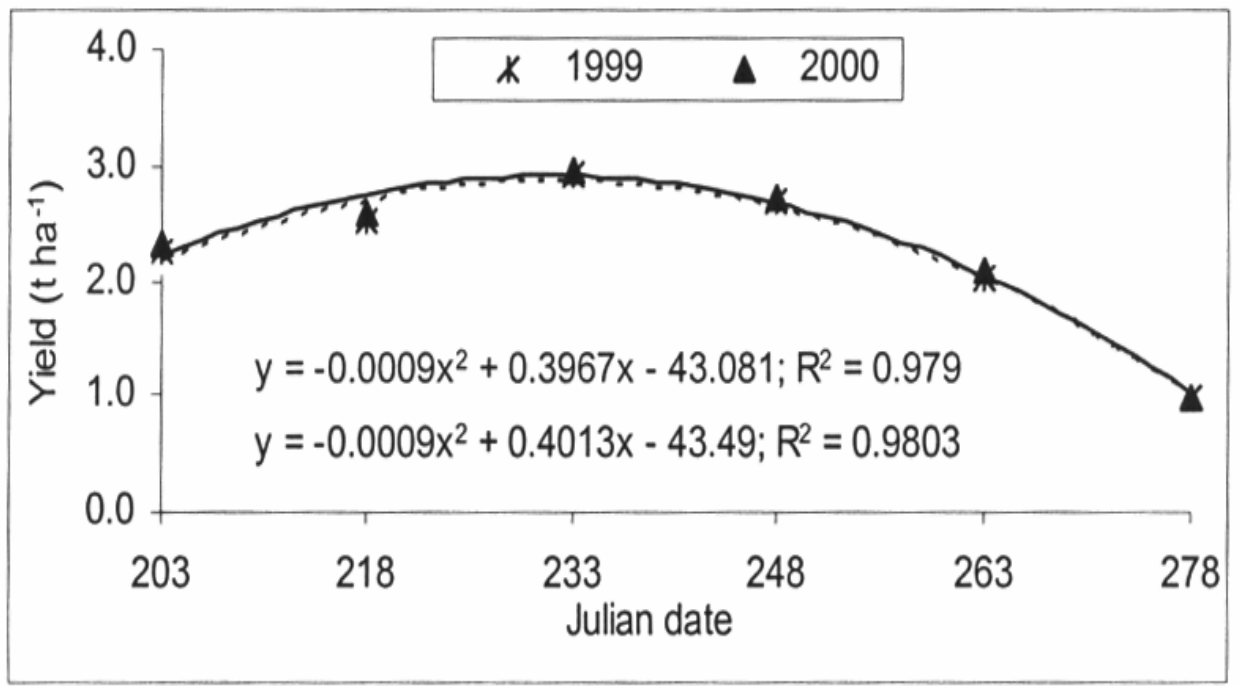

Fig: 3. Grain yield of Basmati fine rice as affected by planting dates (Aman season).

Basmati PNR and Basmati-D gave significantly higher grain yield than the rest of the genotypes. Although Basmati-D produced higher number of panicles, but it failed to produce higher grain yield over Basmati PNR due to lower individual grain weight and high percentage of spikelet sterility. Among the test genotypes, the poor yield was observed in tall genotype Basmati 370 due to weak stem which was prone to pre-mature lodging susceptibility. These findings are in conformity with the results obtained by Ghosh and Ganguly (1994). The grain yield variation due to transplanting of rice on different dates was identified through step up regression analysis. The quadratic relationship was observed between grain yield and planting date irrespective of varieties (Fig. 4). Most of the genotypes showed the highest grain yield transplanted on 22 August. Delayed transplanting beyond 22 August (upto 7 September), the grain yield was declined by $35 \mathrm{~kg} / \mathrm{ha} /$ day for Basmati PNR, $12 \mathrm{~kg} /$ ha/day for Basmati 370, $13 \mathrm{~kg} / \mathrm{ha} /$ day for Basmati 375, and $19 \mathrm{~kg} / \mathrm{ha} /$ day for Basmati-D. Further delayed transplanting beyond 7 September (upto 22 September), grain yield reduction increased. Late planted crop was adversely affected by low temperature during panicle emergence and grain filling period resulting in lower grain yield (Salam et al., 1992). Further advancement of planting after 22 September and onward upto 7 October, grain yield of Basmati PNR and Basmati 375 was reduced drastically to $71 \mathrm{~kg} / \mathrm{ha} /$ day, whereas yield reduction for Basmati 370 and Basmati-D was 56-59 $\mathrm{kg} / \mathrm{ha} /$ day. 


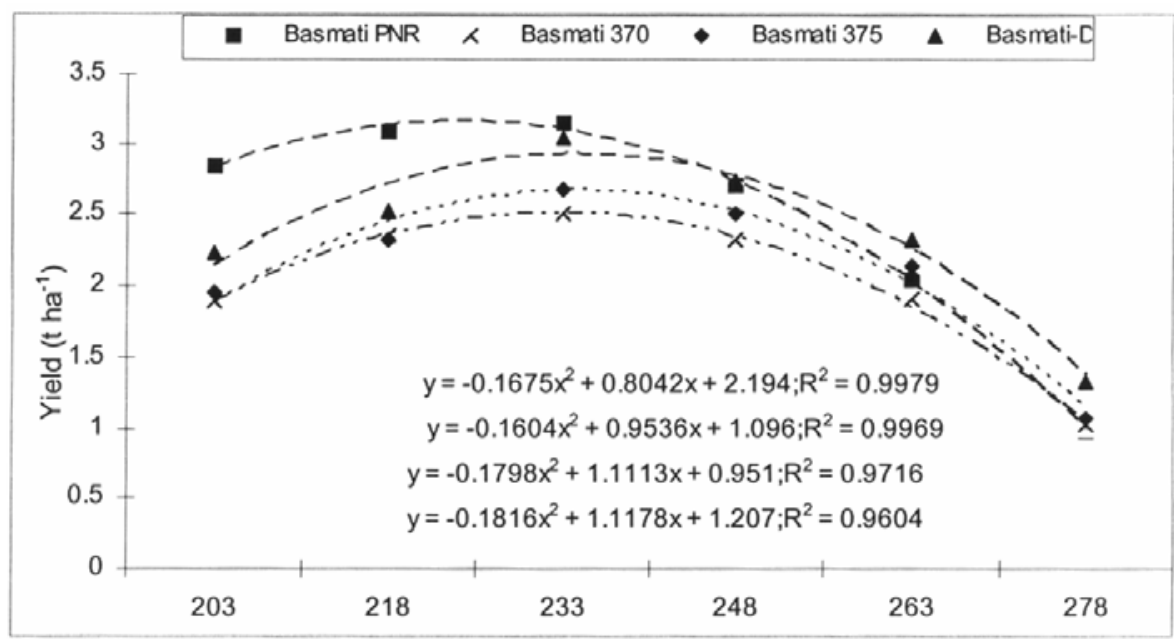

Fig. 4. Relationship of grain yield of Basmati rice as affected by planting date (Aman season).

The optimum date of transplanting of the genotypes was determined by regressing the grain yield with the transplanting dates (Fig. 4). The optimum planting date of Basmati PNR, Basmati 375 was 23 August; Basmati 370 is 29 August, and Basmati-D was 17 August. Estimated date of planting had the similarity with the predicted time. It is clear from the result that most of the genotypes responded well in respect of grain yield when transplanted in August. Similar trend was also observed by Mannan and Siddique (1991) in Aman season. The grain yield reduction of late planted crop was due to incomplete panicle emergence which increased the percentage of spikelet sterility.

\section{Straw yield}

The straw yield decreased with the advancement of planting date. The early planted crop had longer vegetative growth period that produced higher amount of biomass resulting in higher straw yield than the late-planted crop. The high tillering Basmati-D gave the highest straw yield, while the short stature Basmati PNR produced the lowest straw yield irrespective of planting dates (Fig. 5). The tall plant of Basmati 370 and Basmati 375 could not give high straw yield in early in July and August due to low tillering ability. These results are in conformity with the results of Salam et al. (2004). The straw yield variation due to transplanting of rice in different dates was identified through step up regression analysis. It was observed that straw yield linearly decreased with the delay of transplanting irrespective of genotypes. 


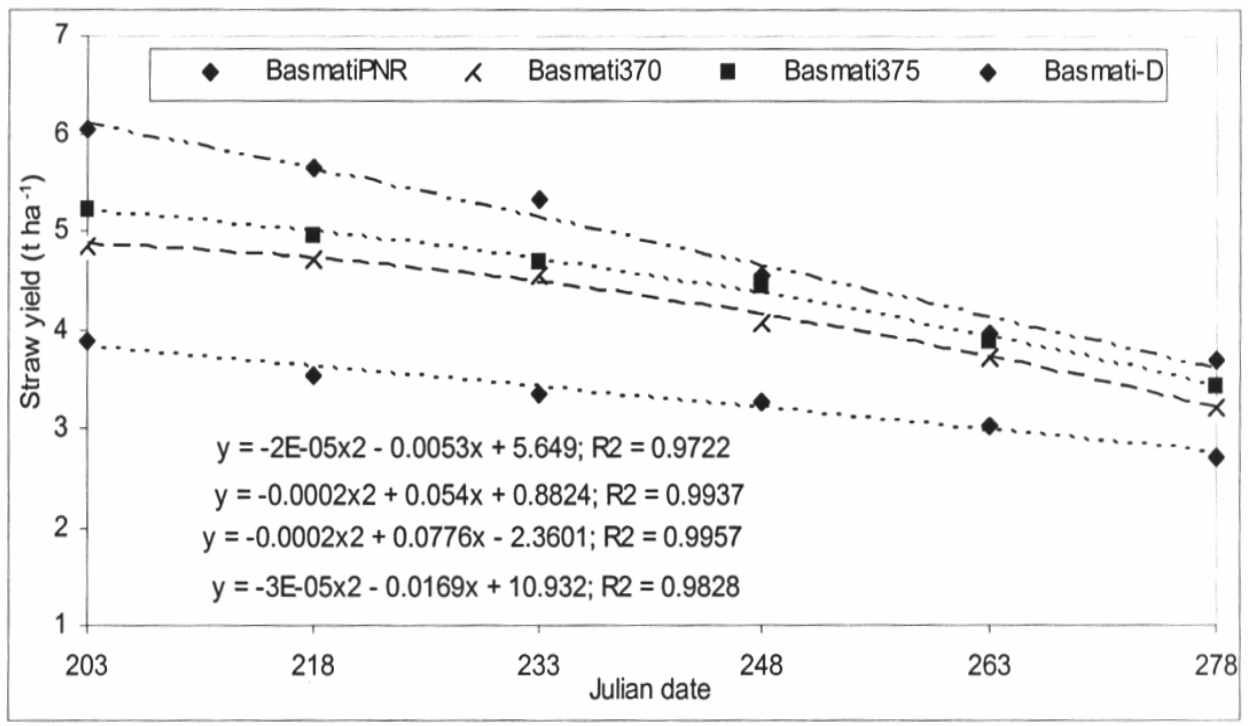

Fig. 5. Relationship of straw yield of Basmati rice as affected by planting date (Aman season).

\section{Flowering behaviour and growth duration}

The crop transplanted on 22 July completed the active vegetative phase and passed the lag vegetative phase and wait for optimum short day length for floral induction and growth duration became longer (128 days) for maturity, while in late planted on 7 October crop, floral initiation occurred just after a minimum period required for the active vegetative phase due to the early fulfillment of the appropriate short day length and matured within 111 days (Fig. 6). The photoperiodic response of rice made its timely floral initiation regardless of normal and late plantings. Similar response was also observed by Salam et al. (1992).

Early planted crop of Basmati PNR, Basmati 370, and Basmati 375 flowered within 22-30 and matured in November (124 days). However, too short growth duration may not produce high yields because of limited vegetative growth where time for tiller production is less. These results are in agreement with that of Maiti and Sen (2003) who found that the growth duration exhibited an increasing trend of early planted crop and decreasing trend of late planted crop. 


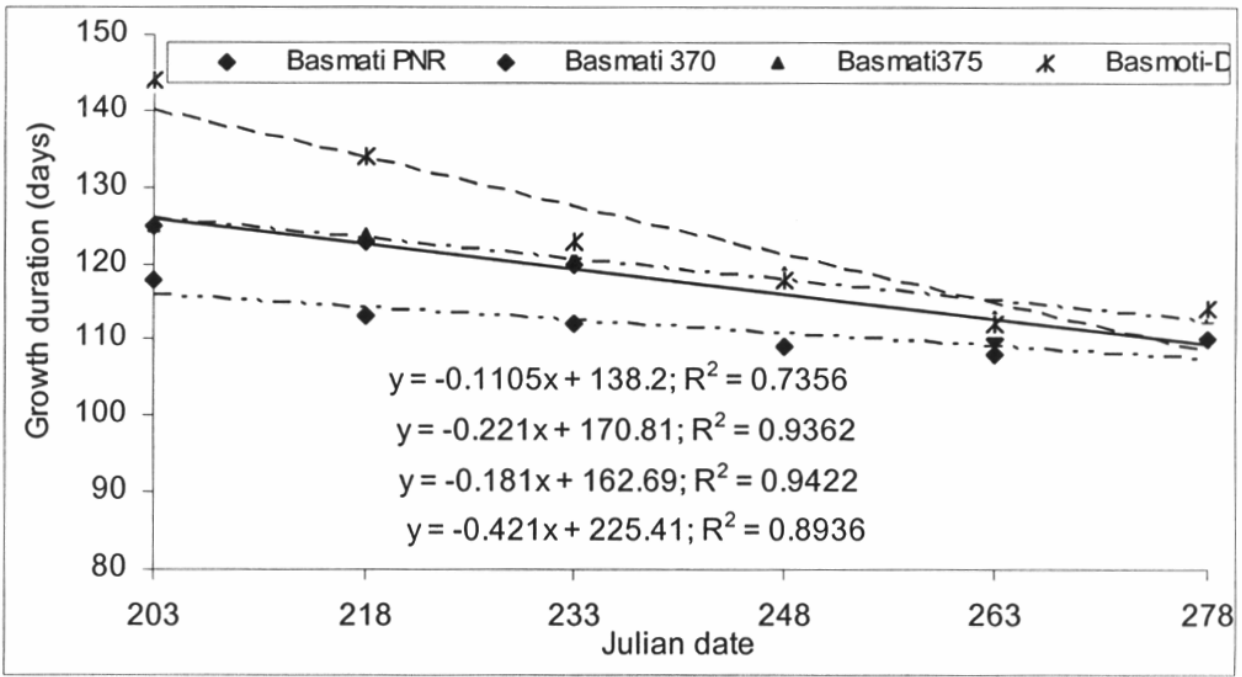

Fig. 6. Growth duration of Basmati rice as affected by planting date (Aman season).

\section{Photoperiod sensitivity}

The degree of photoperiod sensitivity varied from 8.6 to 25.8. The degree of sensitivity was the lowest in Basmati PNR followed by Basmati 375. On the contrary, the degree of sensitivity was the highest in case of Basmati-D (Table 1). This fact well agrees with the results obtained by Ghosh and Saran (1982).

Table 1. Degree of photoperiod sensitivity of Basmati fine rice genotypes in Aman season at Gazipur.

\begin{tabular}{|c|c|c|c|c|}
\hline \multirow[t]{2}{*}{ Genotypes } & \multicolumn{2}{|c|}{ Flowering duration (days) } & \multirow{2}{*}{$\begin{array}{c}\text { Difference } \\
\text { (days) }(X-Y)\end{array}$} & \multirow{2}{*}{$\begin{array}{c}\begin{array}{c}\text { Degree of } \\
\text { sensitivity }\end{array} \\
\mathrm{X}-\mathrm{Y} \times 100 \\
\mathrm{X}\end{array}$} \\
\hline & $\begin{array}{l}\text { Preceded by } \\
\text { long day (X) }\end{array}$ & $\begin{array}{c}\text { Preceded by } \\
\text { short } \\
\text { day }(\mathrm{Y}) \\
\end{array}$ & & \\
\hline Basmati PNR & 93 & 85 & 8 & 8.6 \\
\hline Basmati 370 & 100 & 85 & 15 & 15.0 \\
\hline Basmati 375 & 100 & 88 & 12 & 12.0 \\
\hline Basmati-D & 120 & 89 & 31 & 25.8 \\
\hline
\end{tabular}

Thus, it is better to transplant Basmati PNR and Basmati-D within optimum time 17-21 August, which is most suitable to obtain higher grain yield avoiding long field duration of early planted crop and to give enough time for tillering of late planted crop in Aman season. 


\section{References}

Angrish, R., S.D. Dhiman, A. Rajiv. 1997. Some photoperiodic aspects of Basmati rice growth and development. Adv. Plant Sci. Res. 5-6: 72-80.

Biswas, S.K., B.Banu, K.A.Kabir, F.Begum and N.H. Choudhury. 1992. Physicochemical properties of modern and local rice varieties of Bangladesh. Bangladesh Rice J. 3(1\&2): 128-13 1 .

BRRI (Bangladesh Rice Research Institute). 1997. Variety for Increasing rice production. In: Proc. Workshop on Experience with Modern Rice Cultivation in Bangladesh on 16 April-18 April 1996. Bangladesh Rice Res. Inst., Gazipur. pp. 127-130.

BRRI (Bangladesh Rice Research Institute). 2003. Annual Internal Review held on 19 October - 23 October, Genetic Resources and Seed Divn., Bangladesh Rice Res. Inst., Gazipur, pp. 6-8.

BRRI (Bangladesh Rice Research Institute). 2004. Adunick Dhaner Chash (Bengla), Pub. no. 5. Bangladesh Rice Res. Inst. Gazipur, pp.12-35.

Canet, R. 1986. Effect of sowing time on yield of rice varieties in two locations in Cuba. Intl. Rice Res. Newsl. 11(3): 28.

Chopra, M.K., N. Chapra and S.N. Sinha. 2003. Influence of dates of transplanting on production and quality of scented rice (Oryza saliva) seed. Indian J. Agric. Sci. 73(1): 12-13.

Ghosh, D.C. and S. Ganguly. 1994. Cultural factors affecting growth, lodging and productivity of wet land rice. Indian Agric. 38 (2): 99-103.

Ghosh, S. and S. Saran. 1982. Screening rice varieties for photoperiod sensitivity. Intl. Rice Res. Newsl. 7(1): 4.

Islam, M.R., M.S. Rahman, M.H. Rahman, M.A. Awal and M.G. Hossain. 1999. Effect of date of planting on rice yield and yield attributes of two advance mutants of rice in Aman season. Bangladesh J. Nuclear. Agric. 15: 34-40.

Kropff. M.J. and C.J.T. Spitters. 1991. Introduction to Crop Ecology. Deptt. Theoretical Production Ecology. Wageningen Agril. Univ. pp.1, 10-2.24.

Maiti, P.K., and S.N. Sen. 2003. Crop Mangement for Improving Boro Rice Productivity in West Bengal. Boro Rice. Ed. R.K. Singh, M. Hossain and R. Thakur, Intl. Rice Res. Inst., India Office, Pusa Campus, New Delhi-i 10012, India. pp. 167-173.

Mannan, M.A. and S .B. Siddique. 1991. Effect of seedling age and date of planting on the growth and yield of photoperiod sensitive rice. Bangladesh Rice J. $2(1 \& 2)$ : 2004-206.

Salam, M.A., F. Ali, M.P. Anwar and M.S.U. Bhuiya. 2004. Effect of level nitrogen and date of transplanting on the yield and yield attributes of transplanted Aman rice under SRI method. J. Bangladesh Agril. Univ. 2(1): 3 1-36.

Salam, M.A., M.A. Kabir and N.M. Miah. 1992. Adaptability of photoperiod-sensitive modern rice varieties in the Boro season. Bangladesh Rice J. 3(1\&2): 144-147. 
Singh, D.P. and F.U. Zaman. 1991. Improvement in production and productivity of Basmati rice in Northern India. Rice India 1(2): 34-35.

Singh, K.M., S.K. Pal, U.N. Verma, R. Thakur and M.K. Singh. 1997. Effect of time and methods of planting on performance of rice (Oryza saliva) cultivars under medium land of Bihar Plateau. Indian J. Agron. 42(3): 443-445.

Singh, V.P. and V.K. Singh. 2000. Effect of sowing date and nitrogen level on the productivity of spring sown rice (Oryza sativa) varieties in low hills of Uttaranchal. Indian J. Agron. 45(3): 560-563.

Yoshihashi, T. 2005. Does Drought Condition Induce the Aroma Quality of Aromatic Rice. Japan Intl. Res. Center for Agril. Sci. Food Sci. Divn. Newsletter for Intl. Collaboration. no. 45. Japan. p. 4. 